\title{
Safe Reopening of Schools during COVID-19: An Evaluation of Handwash Facilities and Students' Hand Hygiene Knowledge and Practices
}

\author{
Ojima Zechariah Wada ${ }^{1,2}$, Elizabeth O. Oloruntoba ${ }^{1 *}$
}

\begin{abstract}
${ }^{1}$ Department of Environmental Health Sciences, Faculty of Public Health, College of Medicine, University of Ibadan, Ibadan, NIGERIA
${ }^{2}$ Division of Sustainable Development, College of Science and Engineering, Hamad Bin Khalifa University, Doha, QATAR

*Corresponding Author: li_zzyy@yahoo.com
\end{abstract}

Citation: Wada, O. Z. and Oloruntoba, E. O (2021). Safe Reopening of Schools during COVID-19: An Evaluation of Handwash Facilities and Students' Hand Hygiene Knowledge and Practices. European Journal of Environment and Public Health, 5(2), em0072. https://doi.org/10.21601/ejeph/9704

\section{ARTICLE INFO}

Received: 1 Nov. 2020

Accepted: 7 Dec. 2020

\begin{abstract}
Children are energetic and filled with vigour, the high rate of person-to-person contact at schools could leave the students susceptible to hygiene-related illnesses if appropriate measures are not put in place. The absence of adequate handwash facilities, inadequate hand hygiene knowledge, and poor hand hygiene practices have been reported to be prevalent among schools in Nigeria. The emergence of COVID-19 even makes it more important to provide recent and quality data as schools plan to reopen safely. This study aimed to assess the accessibility of public-school students in Badagry, Lagos State to basic handwash services, as well as their hygiene-related knowledge and practices. A 4-stage sampling method was used to select 5 wards, 5 schools, the classes, and 351 students. A mixed-method which included a semi-structured questionnaire, observational checklist, and a key informant interview guide was used to collect data. Data were inputted into SPSS version 20 and analyzed using descriptive statistics, chi-square, and logistic regression at a $95 \%$ confidence interval. The respondents had a mean age of $15.88 \pm 1.54$ years. All the available wash-hand stations (WHS) were in the toilet blocks. All the male toilet facilities had WHS as opposed to just $60 \%$ of the female facilities. None of the WHS had soap present, while a quarter of the WHS did not have water available. Based on the Joint Monitoring Programme (JMP) classification; none of the WHS provided basic hygiene service, $60 \%$ provided limited service and $40 \%$ provided no service. The majority (83\%) of the students possessed a good knowledge of hand hygiene, however, only less than half (47\%) reported washing their hands with soap and water at school. Factors like age $(\mathrm{p}=0.010)$ and their parents' educational status (mother- $\mathrm{p}=0.002$; father- $\mathrm{p}=0.011$ ) significantly affected the students' knowledge. The absence of basic handwash facilities in all the schools clearly shows the need for rapid intervention, particularly to eliminate gender disparities and to ensure the sustainable availability of sufficient soap and water.
\end{abstract}

Keywords: COVID-19, Joint Monitoring Program (JMP), hand hygiene, schools, handwash, soap and water

\section{INTRODUCTION}

According to the World Bank, the most cost-effective health intervention is hygiene promotion (World Bank, 2016). Advocating for good hand hygiene practice within communities have been proven to lower the incidence of diarrhea by $23-40 \%$ and respiratory infection by about $21 \%$ (Freeman et al., 2014 and Aiello et al., 2008). A randomized control trial revealed that the practice of hand hygiene with soap and water reduced the incidence of diarrhea and impetigo by over $50 \%$ among children, while the incidence of pneumonia lowered by $50 \%$ (Luby et al., 2005). Access to basic hygiene services goes beyond the home setting, as a reasonable amount of time is spent outside. Students spend a significant portion of their childhood at schools, health care workers and patients spend a significant proportion of their time at the hospital, while other adults also spend time at their workplaces. It is therefore essential for basic hygiene services to be provided in all these institutions to reduce the risk of disease transmission (Eawag, 2018; WHO, 2009, 2015).

Furthermore, accessibility to basic hygiene services in schools reduces the possibility of disease transmission between pupils. Schools that lack adequate hygiene facilities are liable to have their students imbibe both a poor attitude towards handwashing and an unhealthy hand hygiene practice, thereby increasing the risk of disease transmission in the school environment (WHO, 2009). Moreover, the possible adverse effects on the health of the students, hygiene-related diseases in students have also been associated with increased 


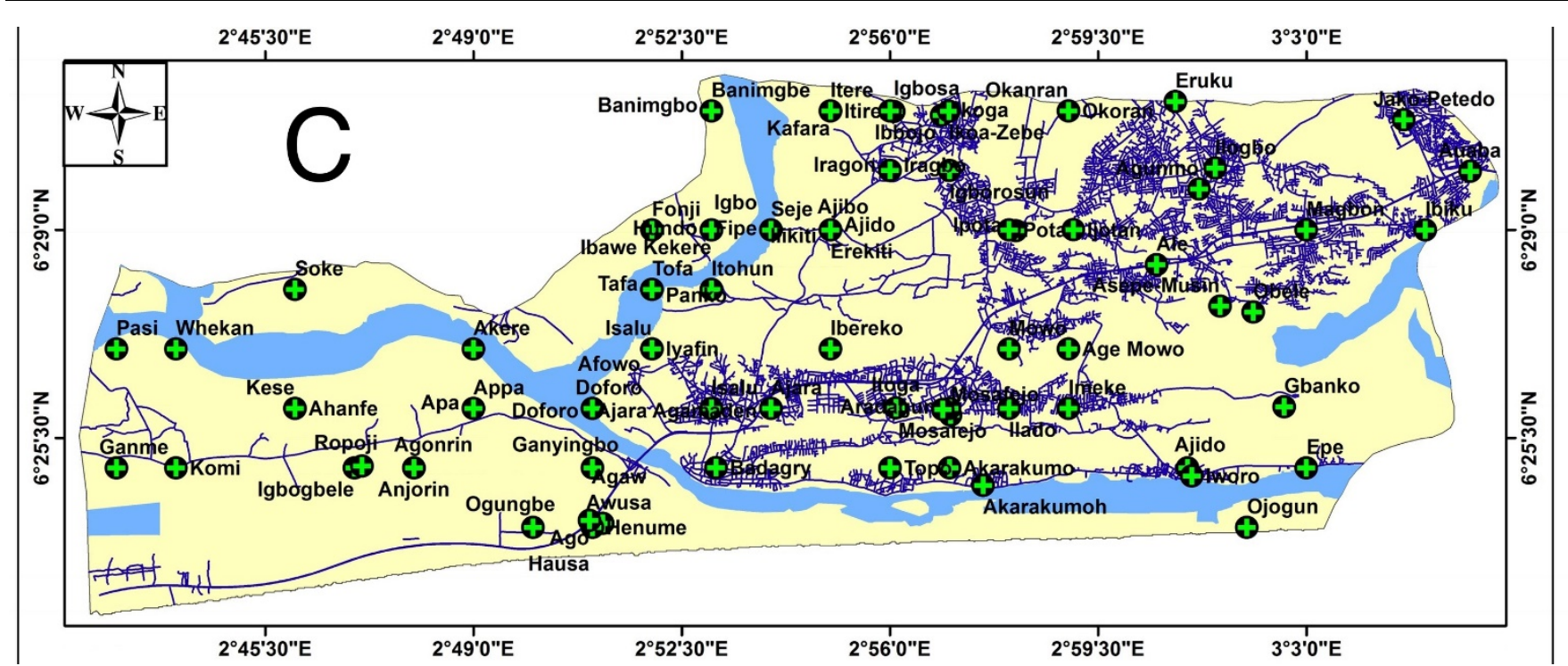

Figure 1. Map of Badagry LGA

absenteeism and decreased academic performance. This increases the likelihood of having a higher proportion of school dropouts, thereby impeding the ability of such adolescents to reap the benefits of educational attainment (Gakidou et al., 2010; Morrissey et al., 2014). The efficacy of handwashing in the reduction of gastrointestinal illnesses among children has been reported to lower school absenteeism by about 29 to $57 \%$ (Wang et al., 2017)

A notable benefit of an enabling environment for handwashing at schools is that it has the potential to significantly alter their behaviour patterns of students, thereby leading to improved hygiene practices both in school, at home, and in their resident community at large (UNICEF, 2011). However, even with the benefits associated with a healthy hand hygiene practice, it has been estimated that as of 2017, Sub-Saharan Africa (SSA) had 27\% coverage of hand wash facilities, while only around $15 \%$ of the population in SSA practiced handwashing with soap and water (WASH Watch, 2017). Besides, less than 50\% of the schools in SSA provided basic hygiene services (WHO/UNICEF, 2018).

Literature has revealed that poor knowledge of healthy hand hygiene practice is also a contributor to the burden of communicable diseases in developing countries (Alyssa et al., 2010; Sibiya and Gumbo, 2013). Some studies conducted in SSA schools have reported the negative impact inadequate hand hygiene knowledge possessed by students had on their practice. A study to determine the extent of handwashing practice among secondary school students in Ebonyi State, Nigeria, disclosed that the level of practice among students was quite low. Poor knowledge possessed by the students was linked to being a factor that affected their hand wash practice (Azuogu et al., 2016). Another study conducted among schools in Kintampo, Ghana reported that around $53 \%$ of the students had never been taught how to wash their hands, while less than a quarter displayed correctly how to wash their hands (Dubik et al., 2018).

The emergence of COVID-19 has further reiterated the importance of handwashing. With schools planning to reopen safely, recent data is required to guide the relevant authorities on ways to improve the students' hygiene practice. Hence, this paper proposed to examine the secondary schools in Badagry Local Government Area for the presence of adequate handwash facilities, and also assess the students' hygienerelated knowledge and practice to provide relevant data to inform local school policies and future interventions.

\section{MATERIALS AND METHODS}

\section{Background to Study Area}

The study was carried out in Badagry Local Government Area (LGA); a coastal settlement in Lagos State. The community has rustic areas and is not as developed as most other LGAs in the State (Ogunbiyi, 2017). It lies close to the Republic of Benin border at Seme. Badagry is $69.19 \mathrm{Km}$ southeast of Lagos, $51.49 \mathrm{Km}$ west of Seme, and bordered by the Gulf of Guinea to the south (Harris and Lynn, 2017). Badagry is situated on latitude: $6^{\circ} 24^{\prime} 54.07$ ' $\mathrm{N}$ and longitude: $2^{\circ} 52$ ' 52.75” E. Badagry LGA consists of 11 wards and 13 public senior secondary schools. The map of the study area is shown in Figure 1.

\section{Study Design and Population}

The survey was cross-sectional in design. The study population included male and female students from public senior secondary schools in Badagry LGA. The sample size of 351 was estimated by using sample size calculation for crosssectional quantitative surveys (Jaykaran and Tamoghna, 2013). A 4-stage sampling method was adopted. The wards were firstly stratified into 5 equal regions based on the total area of the LGA, after which one ward was selected from each region via simple random sampling. A total of 5 out of the 11 wards were selected. One public secondary school was selected from each ward via simple random sampling. The number of students selected from each school was proportionately allocated by comparing the student population of all the selected schools to the proposed sample size of 351 . 


\section{Study Instrument}

A semi-structured, self-administered questionnaire, observational checklist, and key informant interview guide were used. The questionnaire obtained information about the students' socio-demographic characteristics and assessed their handwash knowledge and practice. The observational checklist was used to access the status of the hygiene facilities available at school. Some of the questions were adopted fromCore questions and indicators for monitoring SDG 6 in Schools in the Sustainable Development Goals (WHO/UNICEF, 2016). A key informant interview guide was used to obtain deeper insights about the hygiene facilities from the sanitation and health prefects at the schools.

\section{Data Collection}

Data were collected at the beginning of the 2018/2019 academic session. A total of 351 semi-structured questionnaires were administered to study participants with the assistance of trained enumerators. The enumerators helped ensure that the entire questionnaires were correctly completed by the respondents. Furthermore, the instruments were filled in the absence of their teacher to prevent any undue influence. The environmental assessment was done during school hours to observe how the facilities were used by the students. The interviews were held during break time to avoid distractions from school activities.

\section{Data Management and Analysis}

The data collected was sorted appropriately according to the individual schools and wards. Each questionnaire was given a serial number and cleaned appropriately before inputting and analyzing the data via SPSS 20. Descriptive statistics were used to measure the frequency and proportion of the socio-demographic characteristics of the respondents and the knowledge and practice variables. The outcome variable respondents' knowledge of hand hygiene was measured on an 8-point scale. Those with a score of 6 to 8 were categorized as having good knowledge, while those with a score of 0 to 5 were categorized as having poor knowledge. Inferential statistics like chi-square and logistic regression at $95 \%$ confidence interval were used to measure the associations between the socio-demographic characteristics and knowledge and practice variables. The key informant interviews were transcribed, after which key information concerning their handwash facilities and practice were synthesized.

The handwash stations were categorized based on their availability (number of facilities present in school), functionality (number of facilities in working condition), accessibility (the number of functional facilities accessible to the students at all times), and usage (the number of functional facilities that appeared to be in use). The hygiene facilities were also categorized based on the WHO/UNICEF Joint Monitoring Program (JMP) ladder for hygiene in schools; schools with handwashing facilities with water and soap available at the time of the survey are considered to have 'basic' service. Those with handwashing facilities that have water available at the time of the survey, but no soap, are considered to have 'limited' service, while schools with no
Table 1. Socio-demographic characteristics of respondents

\begin{tabular}{|c|c|c|}
\hline Characteristics & $\begin{array}{c}\text { Frequency } \\
(\mathrm{N}=351)\end{array}$ & $\begin{array}{c}\text { Percentage } \\
\text { (\%) }\end{array}$ \\
\hline \multicolumn{3}{|l|}{ Gender } \\
\hline Male & 159 & 45.3 \\
\hline Female & 192 & 54.7 \\
\hline \multicolumn{3}{|l|}{ Age of respondents } \\
\hline 12 years to 16 years & 238 & 67.8 \\
\hline 17 years to 21 years & 113 & 32.2 \\
\hline \multicolumn{3}{|c|}{ Mother's highest level of education } \\
\hline Primary & 34 & 9.7 \\
\hline Secondary & 176 & 50.1 \\
\hline Tertiary & 124 & 35.3 \\
\hline No formal education & 17 & 4.8 \\
\hline \multicolumn{3}{|c|}{ Father's highest level of education } \\
\hline Primary & 25 & 7.1 \\
\hline Secondary & 160 & 45.6 \\
\hline Tertiary & 156 & 44.4 \\
\hline No formal education & 10 & 2.8 \\
\hline \multicolumn{3}{|l|}{ Ethnic group } \\
\hline Yoruba & 202 & 57.5 \\
\hline Egun & 60 & 17.1 \\
\hline Igbo & 57 & 16.2 \\
\hline Hausa, Igala, Idoma, Tiv & 32 & 9.2 \\
\hline \multicolumn{3}{|l|}{ Religion } \\
\hline Christianity & 238 & 67.8 \\
\hline Islam & 112 & 31.9 \\
\hline Traditional worshipper & 1 & 0.3 \\
\hline
\end{tabular}

facilities or no water available for handwashing are classified as having 'no service' (WHO/UNICEF, 2018).

\section{Ethical Considerations}

Ethical approval was obtained from the University of Ibadan/University College Hospital Research Ethics Committee and the Lagos State Ministry of Education before the survey began. Permission was obtained from the school principals before engaging the students, and assent was also gotten from each student. No undue compensation was offered to the students, they had the right to voluntarily opt-out of the study at any time. The school authorities were given assurance of confidentiality.

\section{RESULTS}

\section{Socio-demographic Characteristics of Respondents}

Details of the respondents' socio-demographic characteristics are present in Table 1 . The respondents had a mean age of $15.88 \pm 1.54$. The dominant religion practiced was Christianity (67.8\%), while the major ethnicity was Yoruba (57.5\%). Table 1 outlines the details of their characteristics. Less than half of their fathers (44.4\%) and mothers (35.3\%) had obtained tertiary education.

\section{Availability and Functionality of Handwash Facilities (HWF)}

All (100\%) of the schools made use of wash-hand basins as their HWF. The wash-hand basins were located within each school's male and female toilet block. All (100\%) male toilet facilities had HWF as opposed to just $60 \%$ of the female toilet compartments leaving $40 \%$ without any HWF. The majority 
Table 2. Number of handwash facilities and wash-hand basins in use by the students

\begin{tabular}{cccc}
\hline Number of Handwash Facilities & $\begin{array}{c}\text { Location of } \\
\text { Handwash Facilities }\end{array}$ & Total \\
\hline & Girl's Only Boy's Only & \\
\hline Available Handwash Facilities & 8 & 12 & 20 \\
\hline Functional Wash-Hand Basins & 8 & 9 & 17 \\
\hline Accessible Wash-Hand Basins & 2 & 6 & 8 \\
\hline Functional Wash-Hand Basins in Use & 4 & 2 & 6 \\
\hline
\end{tabular}

(75\%) of the wash-hand basins in the male toilets were in a functional state (in working condition), while all the basins present in the female toilets were functional. Details of the number of available and functional HWF are revealed in Table 2.

\section{Accessibility of HWF to the Students}

Over half (60.0\%) of the schools had sanitation facilities that were not readily accessible to the students because the facilities were always locked with the keys being with school prefects or cleaners. This restricted the access of students to the hand-wash stations as the keys to some of the toilet blocks seemed difficult to retrieve. It was very difficult for the researchers to access some sanitation facilities due to the bureaucracies in place. These restricted toilet blocks accounted for $52.9 \%$ of the available functional HWF.

\section{Proportion/Number of Wash-hand Basins (WHB) in Use}

The WHBs were closely observed, those completely lined with dry dust and without traces of water were assumed and reported not to be in routine/recent use. Of the entire functional WHBs available, only $35.3 \%$ seemed like they were recently used. Less than a quarter of the functional WHBs (22.2\%) in the boys' toilets had been recently used, as opposed to half (50\%) of the WHBs in the girls' toilet. This was corroborated by the health and sanitation prefects in 2 of the secondary schools when asked about their usage. Their responses were:

"It's not good, the students do not use it, and they don't know how to use it. It's the water that they use to flush that they use to wash their hands"- Health prefect (Girl) for School A4

"We have (wash-hand basins in the toilets), it is working. We don't really use it like that sha, (even though) water flows to the sink. You know most boys they feel what I am washing hands for when they are done"-Sanitation prefect (Boy) for school A5

Table 2 categorizes the handwash facilities based on their availability, functionality, accessibility, and usage, while Figure 2 shows some observed WHBs.

\section{Availability of Water at HWF}

A quarter (25\%) of the wash-hand basins had water flowing through the spigot, half (50\%) of the facilities had water available in containers around the basins, while $25 \%$ of the facilities lacked water.

\section{Availability of Soap at HWF}

Of the entire HWF, soap was unavailable in all (100\%) of the facilities visited during the survey. The sanitation and health prefects were also asked via the KII, their responses were:

"Sometimes if there is still soap we give it to them and it is always there, but some people do take the soap home"Sanitation prefect (Girl) for school A1

"No (there is no soap available), people rinse their hands with only water just like that"- Sanitation prefect (Boy) for school A3

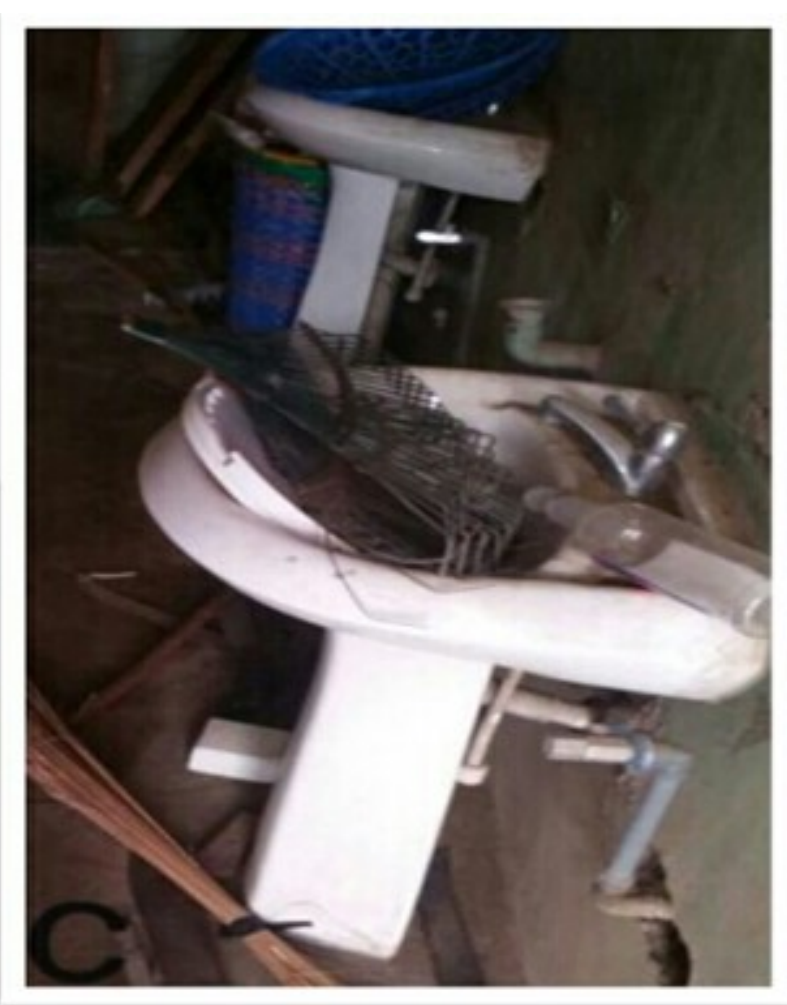

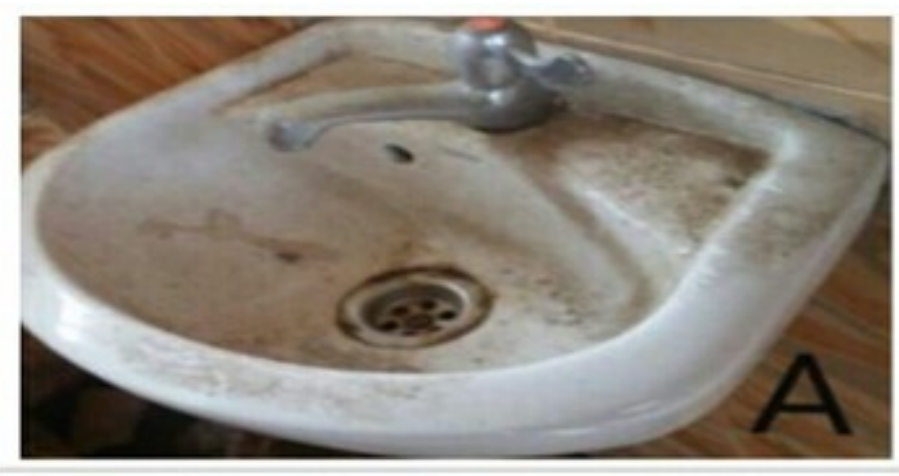

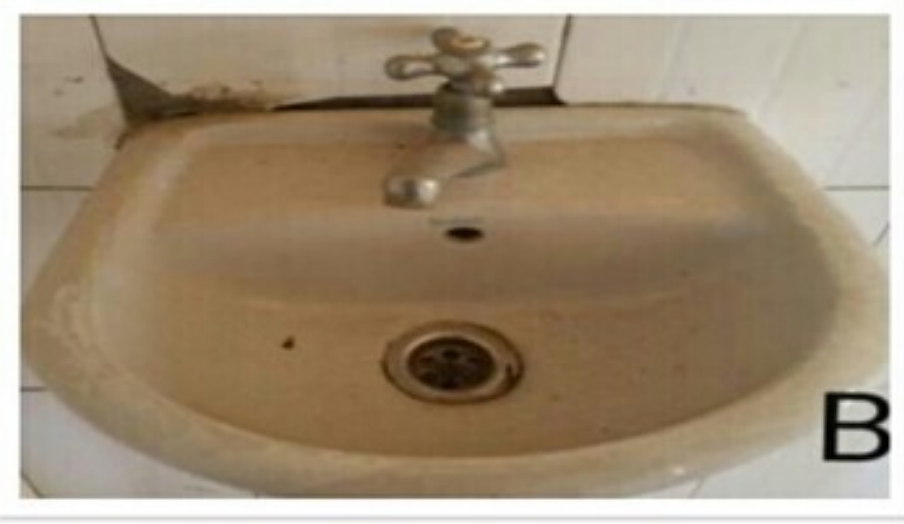

Figure 2. A and B are wash-hand basins apparently lined with dust, while $\mathrm{C}$ are wash hand basins used to store cleaning items 
Table 3. Student to functional hand-wash station for government schools in Badagry LGA

\begin{tabular}{ccccccc}
\hline School & $\begin{array}{c}\text { Total } \\
\text { Student } \\
\text { Population }\end{array}$ & $\begin{array}{c}\text { Boys to } \\
\text { Girls Ratio }\end{array}$ & $\begin{array}{c}\text { Number of } \\
\text { functional hand- } \\
\text { wash stations }\end{array}$ & \multicolumn{2}{c}{$\begin{array}{c}\text { Student to } \\
\text { handwash } \\
\text { station ratio }\end{array}$} \\
\hline & & & Boy & Girl & Boy & Girl \\
\hline I & 756 & $375: 381$ & 2 & 0 & $188: 1$ & Nil \\
\hline II & 2168 & $1112: 1056$ & 2 & 2 & $556: 1$ & $528: 1$ \\
\hline III & 1335 & $685: 650$ & 2 & 0 & $343: 1$ & Nil \\
\hline IV & 1037 & $495: 542$ & 1 & 4 & $495: 1$ & $34: 1$ \\
\hline V & 1107 & $545: 562$ & 2 & 2 & $273: 1$ & $281: 1$ \\
\hline Total & 6403 & $3212: 3191$ & 9 & 8 & $357: 1$ & $399: 1$ \\
\hline
\end{tabular}

Table 4. JMP classification for hygiene

\begin{tabular}{cccc}
\hline $\begin{array}{c}\text { Name of } \\
\text { school }\end{array}$ & $\begin{array}{c}\text { Male/Female } \\
\text { facility }\end{array}$ & $\begin{array}{c}\text { Type of handwash } \\
\text { facility }\end{array}$ & $\begin{array}{c}\text { JMP } \\
\text { classification }\end{array}$ \\
\hline \multirow{2}{*}{ I } & Male & Wash-Hand Basin & No Service \\
Female & Nil & No Service \\
\hline \multirow{2}{*}{ II } & Male & Wash-Hand Basin & No Service \\
& Female & Wash-Hand Basin & Limited Service \\
\hline \multirow{2}{*}{ III } & Male & Wash-Hand Basin & Limited Service \\
& Female & Nil & No Service \\
\hline \multirow{2}{*}{ IV } & Male & Wash-Hand Basin & Limited Service \\
& Female & Wash-Hand Basin & Limited Service \\
\hline \multirow{2}{*}{ V } & Male & Wash-Hand Basin & Limited Service \\
& Female & Wash-Hand Basin & Limited Service \\
\hline
\end{tabular}

“No soap, they (students) just rinse their hands"- Health prefect (Girl) for School A4

"No, not really, it's not available. They (the students) do not really use soaps in washing hands"- Sanitation prefect (Boy) for school A5

\section{Students to Functional Handwash Station Ratio}

The 5 private schools had a total population of 3212 boys and 3191 girls. The ratio obtained for the boys was 357:1, while the ratio for the girls was 399:1. Details of the ratios can be seen in Table 3.

\section{Accessibility of HWF to Disabled Students}

None (0\%) of the HWF had low sinks/basins, flexible spigots, and grab bars available.
JMP Ladder for Hygiene Public Senior Secondary Schools in Badagry LGA

Considering the accessibility of male students to handwashing facilities; $40 \%$ of the schools provided no service (HWF without water) while $60 \%$ of the schools provided limited service (HWF with no soap). When considering the female students; $60 \%$ of the students had access to limited service (HWF with no soap) while $40 \%$ had no service provided (no HWF). This is elucidated in Table 4. The JMP hygiene service ladder is represented in Figure 3.

\section{Knowledge of Respondents about Hand Hygiene}

Of the total respondents, only $65.8 \%$ knew the correct process of handwashing, while almost all the respondents (95.7\%) were aware of why soap is essential for handwashing. The diseases proper handwashing can help prevent as reported by the students were: diarrhoea (58.4\%), malaria (18.2\%), gonorrhoea (7.7\%), and HIV/AIDS (6.6\%). Detailed descriptive statistics of their knowledge are revealed in Table 5. Upon scoring, the majority of the respondents possessed good knowledge (83\%), the average knowledge score obtained was $6.69 \pm 1.19$ with a minimum of 3 and a maximum of 8 . The total obtainable score was 8 .

\section{Association between Respondents' Knowledge of Handwashing and their Socio-demographic Characteristics}

There were statistically significant relationships between the respondents' knowledge and their age $(p=0.010)$, mother's highest level of education ( $\mathrm{p}=0.002$ ), and father's level of education $(p=0.011)$. There was no statistically significant association with their gender $(p=0.512)$, religion $(p=0.183)$, and ethnicity $(\mathrm{p}=0.292)$. Also, the younger students $(12-16$ years) were 2.1 times more likely to possess good knowledge of hand hygiene compared to the older students (17-21 years). Respondents whose fathers and mothers had not attained tertiary education were respectively about 2.2 times and 3.1 times more likely to possess poor knowledge compared to those whose parents had tertiary education. Details of these associations are present in Table 6.

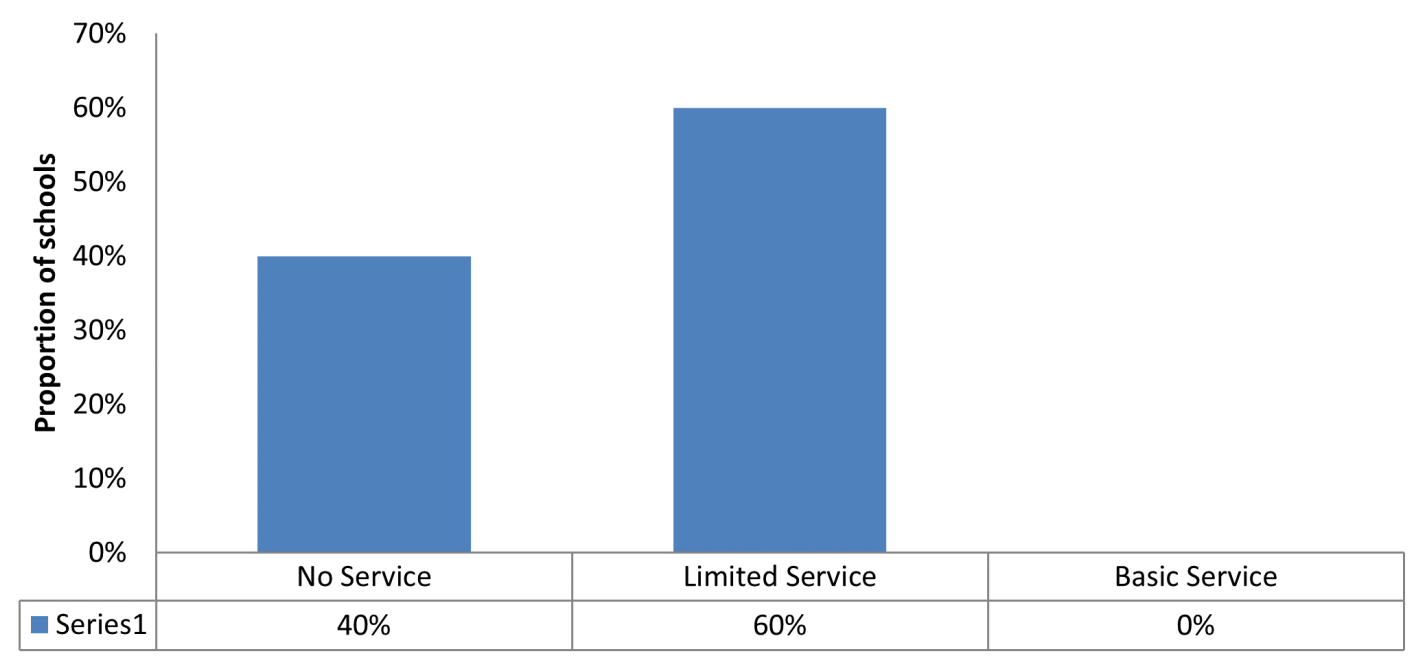

Figure 3. JMP hygiene service ladder for public schools in Badagry LGA 
Table 5. Respondents knowledge on hand hygiene

\begin{tabular}{|c|c|c|}
\hline Knowledge Statement & $\begin{array}{l}\text { Frequency } \\
(\mathrm{N}=351)\end{array}$ & $\begin{array}{l}\text { Proportion } \\
\text { (\%) }\end{array}$ \\
\hline \multicolumn{3}{|l|}{ Correct order of handwashing process } \\
\hline $\begin{array}{l}\text { Wet your hands, then lather with soap, then } \\
\text { scrub, then rinse, then dry }\end{array}$ & 231 & 65.8 \\
\hline \multicolumn{3}{|l|}{$\begin{array}{l}\text { Major reason soap is used for hand- } \\
\text { washing }\end{array}$} \\
\hline To remove germs from the hands & 336 & 95.7 \\
\hline \multicolumn{3}{|l|}{$\begin{array}{c}\text { Proper hand-washing can prevent some } \\
\text { diseases }\end{array}$} \\
\hline Yes & 315 & 89.7 \\
\hline \multicolumn{3}{|l|}{$\begin{array}{l}\text { Reported diseases proper hand-washing } \\
\text { can prevent }\end{array}$} \\
\hline Diarrhoea & 205 & 58.4 \\
\hline Malaria & 64 & 18.2 \\
\hline Gonorrhea & 27 & 7.7 \\
\hline HIV/AIDS & 23 & 6.6 \\
\hline \multicolumn{3}{|l|}{ Germs are present in faeces } \\
\hline Yes & 304 & 86.6 \\
\hline \multicolumn{3}{|l|}{$\begin{array}{c}\text { Germs can be trapped on fingers after } \\
\text { anal cleansing }\end{array}$} \\
\hline Yes & 295 & 84.0 \\
\hline \multicolumn{3}{|l|}{$\begin{array}{c}\text { Handwashing is essential after } \\
\text { defecating }\end{array}$} \\
\hline Yes & 340 & 96.9 \\
\hline \multicolumn{3}{|l|}{ Handwashing is essential after eating } \\
\hline Yes & 323 & 92.0 \\
\hline
\end{tabular}

Table 6. Association between respondents' knowledge and their socio-demographic characteristics

\begin{tabular}{|c|c|c|c|c|}
\hline $\begin{array}{c}\text { Socio-demographic } \\
\text { variables }\end{array}$ & Poor (\%) & Good (\%) & $\begin{array}{c}\chi^{2}(\mathbf{P}- \\
\text { value })\end{array}$ & $\begin{array}{l}\text { OR and } \\
\text { 95\% CI }\end{array}$ \\
\hline \multicolumn{5}{|l|}{ Sex of Respondent } \\
\hline Male & $24(15.1)$ & $135(84.9)$ & \multirow{2}{*}{$\begin{array}{c}0.431 \\
(0.512)\end{array}$} & 0.826 \\
\hline Female & $34(17.7)$ & $158(8$ & & $0.467-1.462$ \\
\hline \multicolumn{5}{|l|}{ Age of Respondents } \\
\hline 12 to 16 years & $31(13.0)$ & 207(87.0) & \multirow{2}{*}{$\begin{array}{c}6.562 \\
\left(0.010^{*}\right) \\
\end{array}$} & \multirow{2}{*}{$\begin{array}{c}0.477 \\
0.269 \text { to } 0.847 \\
\end{array}$} \\
\hline 17 to 21 years & $27(23.9)$ & $86(76.1)$ & & \\
\hline \multicolumn{5}{|l|}{ Religion } \\
\hline Christianity & $35(14.7 \%)$ & $203(85.3 \%)$ & \multirow{2}{*}{$\begin{array}{c}1.772 \\
(0.183)\end{array}$} & \multirow{2}{*}{$\begin{array}{c}0.675 \\
0.377-1.207\end{array}$} \\
\hline Islam & $23(20.4 \%)$ & $90(79.6 \%)$ & & \\
\hline \multicolumn{5}{|l|}{ Ethnic Group } \\
\hline Yoruba & $37(18.3)$ & $165(81.7)$ & \multirow{2}{*}{$\begin{array}{c}1.109 \\
(0.292)\end{array}$} & \multirow{2}{*}{$\begin{array}{c}1.367 \\
0.763-2.449\end{array}$} \\
\hline $\begin{array}{l}\text { Egun, Igbo, Hausa, } \\
\text { Igala, Tiv, Idoma }\end{array}$ & $21(14.1)$ & $128(85.9)$ & & \\
\hline \multicolumn{5}{|l|}{ Mother's Highest } \\
\hline Level of Education & & & \multirow{3}{*}{$\begin{array}{c}9.948 \\
\left(0.002^{\circ}\right)\end{array}$} & \multirow{3}{*}{$\begin{array}{c}3.057 \\
1.487-6.284\end{array}$} \\
\hline $\begin{array}{l}\text { Secondary education } \\
\text { and below }\end{array}$ & $48(21.1)$ & 179(78.9) & & \\
\hline Tertiary education & $10(8.1)$ & $114(91.9)$ & & \\
\hline \multicolumn{5}{|l|}{ Father's Highest } \\
\hline Level of Education & & & \multirow{3}{*}{$\begin{array}{c}6.445 \\
\left(0.011^{*}\right)\end{array}$} & \multirow{3}{*}{$\begin{array}{c}2.177 \\
1.183-4.007\end{array}$} \\
\hline Secondary education & $41(21.0)$ & $154(79.0)$ & & \\
\hline $\begin{array}{c}\text { and below } \\
\text { Tertiary education }\end{array}$ & $17(10.9)$ & $139(89.1)$ & & \\
\hline
\end{tabular}

\section{Respondent's Handwash Practice}

The majority (84.3\%) of the students reported washing their hands while at school. The moments at school they reported washing their hands were: after cleaning the school environment (3.1\%), after break time (10.5\%), before eating (40.2\%), and after using the toilet (42.2\%). Less than half of the
Table 7. Association between practice of hand-washing and socio-demographic characteristics/knowledge of hand hygiene

\begin{tabular}{|c|c|c|c|c|}
\hline $\begin{array}{c}\text { Socio-demographic } \\
\text { Variables }\end{array}$ & $\begin{array}{c}\text { Handwash } \\
\text { practice } \\
\text { with soap } \\
\text { and water } \\
(\%) \\
\end{array}$ & $\begin{array}{c}\text { Poor } \\
\text { hand- } \\
\text { wash } \\
\text { practice } \\
(\%) \\
\end{array}$ & $\begin{array}{c}\chi^{2}(P \\
\text { value })\end{array}$ & $\begin{array}{l}\text { OR and } \\
95 \% \text { CI }\end{array}$ \\
\hline \multicolumn{5}{|l|}{$\begin{array}{c}\text { Gender of } \\
\text { Respondent }\end{array}$} \\
\hline Male & $73(42.2)$ & $96(57.8)$ & 1.246 & 0.787 \\
\hline Female & $107(48.1)$ & $96(51.9)$ & $(0.264)$ & $0.516-1.199$ \\
\hline \multicolumn{5}{|l|}{ Ethnic Group } \\
\hline Yoruba & $106(63.9)$ & $96(51.9 \%)$ & 5.126 & 1.638 \\
\hline $\begin{array}{l}\text { Egun, Igbo, Hausa, } \\
\text { Igala, Idoma, Tiv }\end{array}$ & $60(36.1)$ & $89(48.1 \%)$ & $\left(0.024^{*}\right)$ & $1.067-2.514$ \\
\hline \multicolumn{5}{|l|}{ Age of Respondents } \\
\hline 12 to 16 years & $105(63.3)$ & $133(71.9)$ & 2.991 & 0.673 \\
\hline 16 to 21 years & $61(36.7)$ & $52(28.1)$ & $(0.084)$ & $0.429-1.055$ \\
\hline \multicolumn{5}{|l|}{$\begin{array}{c}\text { Father's Highest } \\
\text { Level of Education }\end{array}$} \\
\hline Secondary and below & $87(52.4)$ & $108(58.4)$ & 1.261 & 0.785 \\
\hline Tertiary & $79(47.6)$ & 77 (41.6) & $(0.261)$ & $0.515-1.198$ \\
\hline \multicolumn{5}{|l|}{ Mother's Highest } \\
\hline Secondary and below & $106(63.9)$ & $121(65.4)$ & 0.092 & 0.934 \\
\hline Tertiary & $60(36.1)$ & $68(34.6)$ & $(0.762)$ & $0.603-1.448$ \\
\hline \multicolumn{5}{|l|}{ Knowledge } \\
\hline Poor & $24(41.4)$ & $34(58.6)$ & 0.975 & 0.751 \\
\hline Good & $142(48.5)$ & $151(51.5)$ & $(0.323)$ & $0.424-1.328$ \\
\hline
\end{tabular}

respondents (47.3\%) reported washing their hands with soap and water while at school.

Association between Respondents' Handwash Practice and Socio-demographic Variables

There were no significant associations between sociodemographic characteristics like the gender of respondents $(p=0.787)$, age of respondents $(p=0.084)$, mother's and father's highest level of education $(\mathrm{p}=0.261$ and $\mathrm{p}=0.762)$, age of respondents $(\mathrm{p}=0.084)$, and the respondents' hand-wash practice. A significant association was only obtained with their ethnicity $(p=0.024)$. Details of these associations can be seen in Table 7 .

\section{DISCUSSION}

\section{Availability of Handwash Facilities}

It is noteworthy that all the schools had a form handwash facility; however this progress was marred by the facts that $40 \%$ of the female toilet blocks were without handwash stations, none of the wash-hand stations had soap present, a quarter of the stations were without water, $52.9 \%$ of the functional stations were not readily accessible and $64.7 \%$ of the wash-hand basins appeared like they were not in routine use. Some factors that contributed to the disparity in the availability of handwash facilities between the male and female toilet blocks was the closure of some new female toilet compartments for "future use" and the school administration's lack of maintenance culture. Another contributory factor could be because male students in the study location were more likely to practice open defecation, 
implying that they visited the male toilet blocks less frequently (Wada et al., 2020). Even though the majority of the wash-hand stations present had water available, literature has revealed that the use of soap and water is more effective in preventing transmission of diarrhoeal diseases because it eradicates bacteria of fecal origin better than the use of only water (Burton et al., 2011). Moreover, it has also been reported that soap removes germs and soil particles more effectively due to the surfactants present and that there is a higher chance of people washing their hands more meticulously when using soap and water (Burton et al., 2011; CDC, 2020; Luby et al., 2005, 2011).

Other surveys in Nigeria reported relatively lower proportions of school handwash points. A survey carried out by Olakanni in 2013 among some public schools in Ogun State and Lagos State, Nigeria had a relatively poor result. It was revealed that only $10 \%$ of the schools surveyed had handwash stations, while none had soap available (Olukanni, 2013). A slight improvement was observed in the UNICEF WASH survey across three States in the country where only $25 \%$ of the schools had handwash basins and soap (UNICEF, 2015a). A school WASH survey carried out in Ibadan city in 2015 reported that wash-hand basins were absent in $77 \%$ of the schools and that soap was only available in $22 \%$ of the schools with washhand basins (Egbinola and Amanambu, 2015). Similarly, a study among primary schools in Ghana reported lower values, $60 \%$ of the schools surveyed had handwash points, out of which only around $30 \%$ provided clean water and soap (Dubik et al., 2018). These results suggest a prevalence of poor handwash culture across secondary schools in Nigeria. Globally, it has been estimated that $53 \%$ of schools provided basic handwash service, while less than $50 \%$ of schools in SSA provided basic hygiene service (WHO/UNICEF, 2018). Public schools in the Badagry community are lagging, as none provided basic service. This is rather unfortunate because hygiene promotion has been acclaimed to be the most costeffective health intervention (World Bank, 2016).

\section{Knowledge and Practice of Handwashing}

The majority (83\%) of the students possessed good hand hygiene knowledge; almost all the students were aware of the importance of handwashing with soap and water after eating and before using the toilet, however, this did not translate into a healthy handwash practice, less than half of the students reported using soap and water at school. Similarly, a survey among schools in Abia State Nigeria revealed that even though $78.7 \%$ of the secondary school students possessed good knowledge, only about $35 \%$ had a good practice, with the inadequacy of handwash facilities being a major factor (Ekeleme et al., 2018). A study to determine the extent of handwash practice among secondary school students in Ebonyi State also revealed that the extent of handwash practice by the students was quite low also due to the inadequacy of required facilities (Azuogu et al., 2016). Furthermore, a Ghanaian survey reported that even though all the students knew it was important to wash hands with soap and water, around half did not wash their hands due to the unavailability of soap and water (Dubik et al., 2018). Another survey among students in Duwakot, Bhaktapur also revealed that all students were aware of the importance of handwashing with soap and water before using eating and after using the toilet, however, only $8.5 \%$ of students practiced this due to the absence of soap (Manandhar and Chandyo, 2017). The inadequacy of handwash facilities in schools negatively impacts students' attitude to hand hygiene, thereby thwarting the efforts of health promotion (Lopez-Quintero et al., 2009)

The significant association derived between the respondents' knowledge and both their parent's level of education and their age have also been reported in other surveys. Students whose parents had attained a tertiary education were more likely to possess a good knowledge of hand hygiene compared to those whose parents had either no education, primary education, or secondary education. The positive impact of the parent's level of education has also been reported in several other studies (Divya et al., 2016; Ekeleme et al., 2018; Rima et al., 2017; Venkatashiva et al., 2017). The younger respondent (12 to 16 years) had a higher level of knowledge compared to the older students (17 to 21 years). This is like results obtained from a study to assess the hand wash knowledge of secondary school students in Abia State (Ekeleme et al., 2018). The absence of significant associations between the respondents' handwash practice at school and variables like gender, parent's highest level of education, age, and knowledge level further buttresses the premise that healthy hand hygiene practice is unachievable without the availability of adequate hygiene facilities.

\section{CONCLUSION}

There is an apparent need for an overall improvement in the condition of the handwash facilities in Badagry LGA public schools. The facilities available are not adequate to curb the spread of COVID-19 and other related diseases at school. The absence of soap in all the wash hand stations restricted access to the facilities and the unavailability of handwash stations in $40 \%$ of the female toilets are some of the major challenges that need to be resolved. The school authorities and teachers need to be sensitized about the importance of making soap available and ensuring the facilities are always accessible to all the students. The schools also need to create an enabling environment to encourage the practice of healthy handwashing through routine public demonstrations or group handwashing sessions. Subsequent interventions should ensure that adequate socially inclusive facilities are provided for both genders. A sustainable scheme on how to ensure soap and water is always available long after the intervention is also integral. Since the students' handwash knowledge was influenced by their parents' educational status, it is also recommendable that the Parents-Teachers-Association (PTA) meetings could be used as a platform to educate the parents about the healthy handwash practice. 


\section{REFERENCES}

Aiello, A. E., Coulborn, R. M., Perez, V. and Larson, E. L. (2008). Effect of hand hygiene on infectious disease risk in the community setting: a meta-analysis. external icon. Am J Public Health, 98(8), 1372-1381. https://doi.org/10.2105/ AJPH.2007.124610

Alyssa, V., Bizu, G., Nigusu, A., Abera, K., Yemane, B. and Michelle, A. W. (2010). Knowledge, Attitudes, and Practices (KAP) of Hygiene among School Children in Angolela, Ethiopia. J Prev Med Hyg, 51(2), 73-79. https://doi.org/10.15167/2421-4248/jpmh2010.51.2.216

Azuogu, V. C., Cajetan, I. I., Ignatius, O. N., Benedict, N. A. and Chinagorom, O. (2016). Extent of Handwashing Practice among Secondary School Students in Ebonyi State. Int J Educ Learn Dev., 4(7), 11-22.

Burton, M., Emma., Peter, D., Gaby, J., Val C. and Wolf-Peter, S. (2011). Effect of Handwashing with Water or Soap on Bacterial Contamination of Hands. Int J Environ Res Public Health, 8(1), 97-104. https://doi.org/10.3390/ijerph 8010097

CDC. (2020). Handwashimg: Clean Hands Save Lives. Available at: https://www.cdc.gov/handwashing/show-me-thescience-handwashing.html

Divya, S., Saju, C. R., Navya C. J., Joshy, V. M., Jini, M. P. and Radhamani, M. V. (2016). A study on selected behavioral factors of mothers influencing acute diarrhoea in underfive children in a rural part of Kerala, India. International Journal of Community Medicine and Public Health, 3, 22112216.https://doi.org/10.18203/2394-6040.ijcmph20162572

Dubik, S., Addo, H., Ojo, L., Amegah, K., Loveland, F., Bechala, B. and Benjamin, B. (2018). Hand washing knowledge and practices among public primary schools in the Kintampo Municipality of Ghana. International Journal of Community Medicine and Public Health, 5, 2205. https://doi.org/ 10.18203/2394-6040.ijcmph20182146

Eawag. (2018). Institutional WASH. Available at: https://www.eawag.ch/en/department/sandec/projects/ses p/institutional-wash/

Egbinola, C. N. and Amanambu, A. C. (2015). Water supply, sanitation and hygiene education in secondary schools in Ibadan, Nigeria. In D. Szymańska and S. Środa-Murawska (Eds.), Bulletin of Geography. Socio-economic Series, 29, 3146. https://doi.org/10.1515/bog-2015-0023

Ekeleme, N. C., Egwuonwu, K. I., Iwuoha, E. C. and Ogunsola, A. S. (2018). Assessment of hand washing knowledge and practice among secondary school students in Aba. Abia State Abia State University Medical Students' Association Journal, 11(1), 18.

Freeman, M. C., Stocks, M. E., Cumming, O., Jeandron A., Higgins, J. P. T. and Wolf, J. (2014). Hygiene and health: Systematic review of handwashing practices worldwide and update of health effects. Trop Med Int Heal., 19, 906-916. https://doi.org/10.1111/tmi.12339
Gakidou, E., Cowling, K., Lozano, R. and Murray, C. J. (2010). Increased educational attainment and its effect on child mortality in 175 countries between 1970 and 2009: a systematic analysis. Lancet, 376, 959-974. https://doi.org/ 10.1016/S0140-6736(10)61257-3

Harris, L. (2017). Sea ports and sea power: African maritime cultural landscapes. Springer. https://doi.org/10.1007/9783-319-46985-0

Jaykaran, C. and Tamoghna, B. (2013). How to Calculate Sample Size for Different Study Designs in Medical Research? Indian J Psychol Med., 35(2), 121-126. https://doi.org/10.4103/0253-7176.116232

Lopez-Quintero, C., Freeman, P., and Neumark, Y. (2009). Hand washing among school children in Bogotá, Colombia. Am J Public Health, 99(1), 94-101. https://doi.org/10.2105/AJPH.2007.129759

Luby, S., Agboatwalla, M., Feikin, D., Painter, J., Billhimer, W., Altaf, A. and Hoekstra, M. (2005). Effect of handwashing on child health: A randomised controlled trial. Lancet, 366. 225-233. https://doi.org/10.1016/S0140-6736(05)66912-7

Manandhar, P. and Chandyo, R. K. (2017). Hand washing knowledge and practice among school going children in Duwakot, Bhaktapur: A cross sectional study. Journal of Kathmandu Medical College, 6(3), 21. https://doi.org/ 10.3126/jkmc.v6i3.19827

Morrissey, T. W., Hutchison, L. and Winsler, A. (2014). Family income, school attendance, and academic achievement in elementary school. Dev. Psychol., 50, 741. https://doi.org/10.1037/a0033848

Ogunbiyi, (2017). Aboru as Metaphor for Rural Lagos. Available at: www.lagosstate.gov.ng/blog/2017/07/05/ aboru-as-metaphor-for-rural-lagos/

Olukanni, D. O., Aridegbe, O. A., Awofeso, A. S. and Ekwulugo, N. S. (2012). Pilot Study Assessing Water Sanitation and Hygiene (WaSH) Program in Public Secondary Schools in South-Western Nigeria [Poster presentation]. UNC Water and Health Conference, Chapel Hills, USA.

Rima, K. S., Prem, K. S., Jitendra, K. S., Sudip, C. and Sanjeev, K. S. (2017). Assessment of the Knowledge, Attitude and Practice Regarding Water, Sanitation and Hygiene among Mothers of Under-five Children in Rural Households of Saptari District, Nepal. American Journal of Public Health Research, 5(5), 163-169. https://doi.org/10.12691/ajphr-5 5-5

Sibiya, J. E. and Gumbo J. R. (2013). Knowledge, attitude and practices (KAP) survey on water, sanitation and hygiene in selected schools in Vhembe District, Limpopo, South Africa. Int J Environ Res Public Health, 10(6), 2282-2295. https://doi.org/10.3390/ijerph10062282

UNICEF. (2011). Water, Sanitation and Hygiene for School children in Emergencies: A Guidebook for Teachers. Available at: https://www.unicef.org/disabilities/files/ WASH_in_Schools_in_Emergencies_Guidebook_for_teach ers_.pdf 
Venkatashiva, R. B., Yadlapalli, S. K., Chandrakant, S. P., Anil, K. G., and Anand, K. (2017). Water and Sanitation Hygiene Practices for Under-Five Children among Households of Sugali Tribe of Chittoor District, Andhra Pradesh, India. Volume 2017, Article ID 7517414. https://doi.org/10.1155/2017/ 7517414

Wada, O. Z., Oloruntoba, E. O., Mumuni, A. and Aluko, O. O. (2020). Classification of sanitation services and students' sanitation practices among schools in Lagos, Nigeria. Environment and Natural Resources Research, 10(3), 55-68. https://doi.org/10.5539/enrr.v10n3p55

Wang, Z., Lapinski, M., Quilliam, E., Jaykus, L. A. and Fraser, A. (2017). The effect of hand-hygiene interventions on infectious disease-associated absenteeism in elementary schools: A systematic literature review. Am J Infect Control, 45, 682-689. https://doi.org/10.1016/j.ajic.2017.01.018

WASH Watch. (2017). Counting how many people have water, sanitation and hygiene by Stuart Kempster. Available at: https://www.washwatch.org/en/blog/counting-howmany-people-have-water-sanitation-and-hygiene/
WHO. (2009). Water, sanitation and hygiene standards for schools in low-cost settings. In J. Adams, J. Bartram, Y. Chartier and J. Sims (Eds.), WHO Library Cataloguing-inPublication Data.

WHO. (2015). Monitoring WASH in Institutions. Available at: http://www.who.int/water_sanitation_health/monitoring/ coverage/monitoring-wash-in-institutions/en/

WHO/UNICEF. (2016). Core questions and indicators for monitoring WASH in Schools in the Sustainable Development Goals. ISBN TBC (version November 2016)

WHO/UNICEF. (2018). Wash in Schools: Drinking Water, Sanitation and Hygiene in Schools. Available at: https://washdata.org/monitoring/schools

World Bank. (2016). Globally, periods are causing girls to be absent from school. Available at: http://blogs.worldbank. org/education/globally-periods-are-causing-girls-beabsent-school 